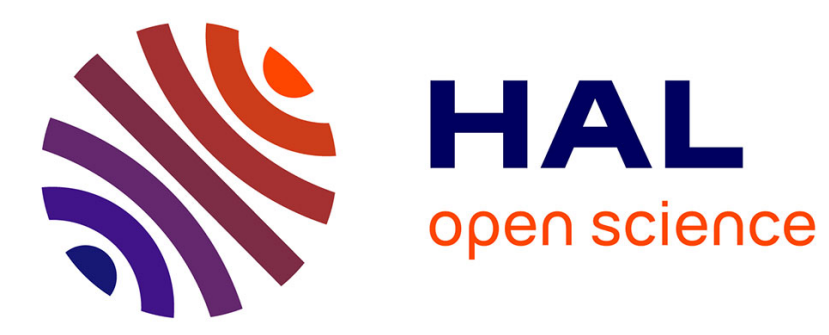

\title{
Shoreline instability under low-angle wave incidence
}

\author{
Déborah Idier, Albert Falqués, Gerben Ruessink, Roland Garnier
}

\section{To cite this version:}

Déborah Idier, Albert Falqués, Gerben Ruessink, Roland Garnier. Shoreline instability under lowangle wave incidence. Journal of Geophysical Research: Earth Surface, 2011, 111 (F4), 12 p. 10.1029/2010JF001894 . hal-00635211

\section{HAL Id: hal-00635211 \\ https: / hal-brgm.archives-ouvertes.fr/hal-00635211}

Submitted on 24 Oct 2011

HAL is a multi-disciplinary open access archive for the deposit and dissemination of scientific research documents, whether they are published or not. The documents may come from teaching and research institutions in France or abroad, or from public or private research centers.
L'archive ouverte pluridisciplinaire HAL, est destinée au dépôt et à la diffusion de documents scientifiques de niveau recherche, publiés ou non, émanant des établissements d'enseignement et de recherche français ou étrangers, des laboratoires publics ou privés. 


\section{- Shoreline instability under low-angle wave incidence}

D. Idier

2 BRGM, 3 Avenue C. Guillemin, BP 6009, 45060 Orléans Cedex 2, France

A. Falqués

3 UPC, C/ Jordi Girona 1-3, Modul B4/B5, despatx 103 - E-08034, Barcelona,

4 Catalonia, Spain

B.G. Ruessink

5 Utrecht University, Institute for Marine and Atmospheric Research Utrecht,

6 Faculty of Geosciences, Department of Physical Geography, P.O. box 80115,

73508 TC Utrecht, The Netherlands

R. Garnier

\& Instituto de Hidráulica Ambiental IH Cantabria, Universidad de Cantabria,

9 ETSI Caminos Canales y Puertos, Avda. los Castros s/n, 39005 Santander,

10 Cantabria, Spain

D. Idier, BRGM, 3 Avenue C. Guillemin, BP 6009, 45060 Orléans Cedex 2, France. (d.idier@brgm.fr)

A. Falqués, UPC, C/ Jordi Girona 1-3, Modul B4/B5, despatx 103 - E-08034, Barcelona, Catalonia, Spain. (falques@fa.upc.edu) 


\section{${ }_{11}$ Abstract.}

The growth of megacusps as shoreline instabilities is investigated by ex-

amining the coupling between wave transformation in the shoaling zone, longshore transport in the surf zone, cross-shore transport, and morphological evolution. This coupling is known to drive a potential positive feedback in case of very oblique wave incidence, leading to an unstable shoreline and the consequent formation of shoreline sandwaves. Here, using a linear stability model based on the one-line concept, we demonstrate that such instabilities can also develop in case of low-angle or shore-normal incidence, under certain conditions (small enough wave height and/or large enough beach slope). The wavelength and growth time scales are much smaller than those of highangle wave instabilities and are nearly in the range of those of surf zone rhythmic bars, $\mathrm{O}\left(10^{2}-10^{3} \mathrm{~m}\right)$ and $\mathrm{O}(1-10$ days $)$, respectively. The feedback mechanism is based on: (1) wave refraction by a shoal (defined as a crossshore extension of the shoreline perturbation) leading to wave convergence shoreward of it, (2) longshore sediment flux convergence between the shoal and the shoreline, resulting in megacusp formation, and (3) cross-shore sed-

B.G. Ruessink, Utrecht University, Institute for Marine and Atmospheric Research Utrecht, Faculty of Geosciences, Department of Physical Geography, P.O. box 80115, 3508 TC Utrecht, The Netherlands. (b.g.ruessink@uu.nl)

R. Garnier, IH Cantabria, Universidad de Cantabria, Avda. los Castros s/n, 39005 Santander, Cantabria, Spain. (garnierr@unican.es) 
${ }_{28}$ iment flux from the surf to the shoaling zone, feeding the shoal. Even though

${ }_{29}$ the present model is based on a crude representation of nearshore dynam-

so ics, a comparison of model results with existing $2 \mathrm{DH}$ model output and lab-

${ }_{31}$ oratory experiments suggests that the instability mechanism is plausible. Ad-

32 ditional work is required to fully assess whether and under which conditions

${ }_{33}$ this mechanism exists in nature. 


\section{Introduction}

34 
55

system self-organizes to produce certain patterns, both morphological and hydrodynamic (see, e.g., Reniers et al. [2004]; Garnier et al. [2008]). In the case of oblique wave incidence, a meandering of the longshore current is also essential to the instability process [Garnier et al., 2006]. Two important characteristics of all available models of the selforganized formation of rhythmic surf zone bars are that they (1) are essentially based on sediment transport driven by the longshore current and rip currents only, i.e. ignore cross-shore transport induced by undertow and wave non-linearity and (2) do not consider morphological changes beyond the offshore reach of the rip-current circulation.

Rhythmic shorelines can also develop as a result of an instability not related to bedsurf coupling. Ashton et al. [2001] and Ashton and Murray [2006a, b] have shown that sandy shorelines are unstable for wave angles (angle between wave fronts and the local shoreline orientation) larger than about $42^{\circ}$ in deep water, leading to the formation of shoreline sandwaves, cuspate features and spits. Falqués and Calvete [2005] have found that the initial characteristic wavelength of the emerging sandwaves is in the range of 3 to $15 \mathrm{~km}$, i.e., much larger than that of surf zone rhythmic bars. This instability caused by high-angle waves will henceforth be referred to as HAWI (High-Angle Wave Instability). The physical mechanism can be explained as follows. For oblique wave incidence, there are essentially two counteracting effects. On one hand, the angle relative to the local shoreline is larger on the lee of a cuspate feature than on the updrift side. This tends to cause larger alongshore sediment flux at the lee and thereby divergence of sediment flux along the bump, which therefore tends to erode. On the other hand, since the refractive wave ray turning is stronger at the lee than at the updrift flank, there is more wave energy 


\section{ten}

p

the development of the cuspate feature. In contrast to the bed-surf instability for rhythmic

surf zone bars, this instability mechanism depends essentially on the coupling between the

surf and shoaling zones. Indeed, the gradients in alongshore sediment flux that induce

bathymetric changes in the surf zone occur because of wave field perturbations induced by

bathymetric features in the shoaling zone. Thus, in order to achieve a positive feedback,

the shoals (or the bed depressions) in the surf zone must extend into the shoaling zone.

This is achieved by the cross-shore sediment fluxes induced, for instance, by wave non-

linearity, gravity and undertow, which force the cross-shore shoreface profile to reach an equilibrium profile. HAWI may provide an explanation for the self-organized formation of some long shoreline sand waves which are reported in the literature [Verhagen, 1989; Inman et al., 1992; Thevenot and Kraus, 1995; Ruessink and Jeuken, 2002; DavidsonArnott and van Heyningen, 2003].

On the other hand, some observations for low incidence angles show that longshore currents can converge on megacusps because of wave refraction [Komar, 1998]. Such current convergence may lead to longshore sediment flux convergence and hence to megacusp growth. If the submerged part of the megacusp grows and extends far enough into the shoaling zone (due to the cross-shore transport leading to an equilibrium profile), wave refraction would be enhanced and a positive feedback would arise. This might provide a mechanism for shoreline instability formation under low-angle wave incidence that bears 
A Cartesian coordinate system is used, with $x$ increasing seaward in the unperturbed cross-shore direction and $y$ running alongshore (Figure 1). The position of the shoreline is given by $x=x_{s}(y, t)$, where $t$ is time and $\bar{D}$ is the active water depth (as defined by Falqués and Calvete [2005]), which is of the order of the depth of closure. This active water depth is directly related to the one-line model concept, for more details, see Falqués and Calvete [2005]. The transport rate $Q$ is computed according to the longshore sediment transport equation of Ozasa and Brampton [1980]. In this formulation, $Q$ is the sum of two terms: the first one $\left(Q_{1}\right)$ is driven by waves approaching the shore at an angle and is equivalent to the CERC formula [USACE, 1984], and the second one $\left(Q_{2}\right)$ takes into account the influence of wave set-up induced currents related to the alongshore gradient in the wave height. 


$$
Q=\mu H_{b}^{5 / 2}\left(\sin \left(2\left(\theta_{b}-\phi\right)\right)-r \frac{2}{\beta} \cos \left(\theta_{b}-\phi\right) \frac{\partial H_{b}}{\partial y}\right)
$$

where $H_{b}$ is the (rms) wave height at breaking (index $b$ ), $\theta_{b}$ is the angle between wave fronts and the unperturbed coastline at breaking, and $\phi=\tan ^{-1}\left(\partial x_{s} / \partial y\right)$ is the local orientation of the perturbed shoreline. $\beta$ is the beach slope at the instantaneous shoreline (i.e. the waterline). The constant $\mu$ is proportional to the empirical parameter $K_{1}$ of the original CERC formula and is $\sim 0.1-0.2 \mathrm{~m}^{1 / 2} \mathrm{~s}^{-1}$. For the reference case of this paper, a value, $\mu=0.15 \mathrm{~m}^{1 / 2} \mathrm{~s}^{-1}$, was chosen, which corresponds to $K_{1}=0.525$. The nondimensional parameter $r$ is equal to $K_{2} / K_{1}$, where $K_{2}$ is the empirical parameter of Ozasa and Brampton [1980]. According to Horikawa [1988], $r$ ranges between 0.5 and 1.5, whereas Ozasa and Brampton [1980] suggest a value of 1.62 . The value $r=1$ is used for the present reference case, which is equivalent to $K_{2}=K_{1}$ and has been used in several earlier studies on shoreline instabilities [Bender and Dean, 2004; List et al., 2008; van den Berg et al., 2011]. However, the term $Q_{2}$ is not always taken into account, and its validity and application range are uncertain. In section 3.2, we will study the sensitivity of our results to the value of $r$.

Some discussion exists about the capacity of the CERC formula $\left(Q_{1}\right)$ to predict correctly gradients in alongshore sediment transport in the presence of bathymetric perturbations [List et al., 2006, 2008; van den Berg et al., 2011]. The results of List and Ashton [2007] suggest that the CERC formula predicts qualitatively correct transport gradients for large scale shoreline undulations (alongshore lengths of 1-8 km). The term $Q_{2}$ was introduced to describe the sediment transport resulting from alongshore variations in the breaker wave height induced by diffraction near coastal structures. These breaker-height variations in- 


$$
D(x, y, t)=D_{0}(x)-\beta f(x) x_{s}(y, t)
$$

where $D(x, y, t)$ and $D_{0}(x)$ are the perturbed and unperturbed water depth, respectively, and $f(x)$ is a shape function. Figure 2a shows some examples of possible perturbation profiles: constant bed perturbation in the surf zone and decreasing exponentially in the offshore direction (P1), bed perturbation decreasing exponentially in the offshore direction from the coast (P2), and bed perturbation similar to a shoal (P3 and P4).

The offshore extension of the bathymetric perturbation is controlled by its "characteristic" length, $x l$, which is a free parameter in the model. It was shown by Falqués and Calvete [2005] that the coupling between the surf and shoaling zones is crucial for HAWI. This is accomplished only if $x l$ is at least a couple of times larger than the surf zone width. The parameter $x l$ can be seen as a way to parameterise cross-shore sediment transport, especially between the surf and shoaling zones. This makes HAWI essentially 
rip channels. The changes in the shoreline cause changes in the bathymetry (both in the surf and shoaling zones), which in turn cause changes in the wave field. The changes in the wave field affect the sediment transport that drives shoreline evolution. Therefore, the shoreline, the bathymetry and the wave field are fully coupled.

Following the linear stability concept, the perturbation of the shoreline is assumed to be

$$
x_{s}(y, t)=a e^{\sigma t+i K y}+\text { c.c. }
$$

where $a$ is a small amplitude. For each given (real) wavenumber, $K$, this expression is inserted into the governing equation (eq. 1), and into the perturbed bathymetry equation (eq. 3). By computing the perturbed wave field and inserting $H_{b}$ and $\theta_{b}$ in eq. 1 , the complex growth rate, $\sigma(K)=\sigma_{r}+i \sigma_{i}$, is determined. All of the equations are linearized with respect to the amplitude, $a$. Then, for those $K$ such that $\sigma_{r}(K)>0$ a sandwave with wavelength $\lambda=2 \pi / K$ tends to emerge from a positive feedback between the morphology and the wave field. The pattern that has the maximum growth rate is called the Linearly Most Amplified mode (LMA mode).

\section{Numerical experiments on idealised cases}

To investigate the possible mechanism causing shoreline instabilities under low wave incidence angles, numerical experiments on idealised cases are performed. First, numerical experiments and results are given. Then, a sensitivity study is done to assess better the results. 


\subsection{Instabilities versus beach slope and wave incidence angle}

\subsubsection{Configuration}

A Dean profile (Figure 2b) is chosen as the equilibrium profile, using various beach slopes (Figures $2 \mathrm{~b}$ and $\mathrm{c}$ ). The adopted profile is given by:

$$
D_{0}(x)=b\left(\left(x+x_{0}\right)^{2 / 3}-x_{0}^{2 / 3}\right)
$$

which has been modified from the original Dean profile to avoid an infinite slope at the shoreline. The constants $b$ and $x_{0}$ are determined from the prescribed slope $\beta$ at the coastline and the prescribed distance $x_{c}$ from the coastline to the location of the closure depth $D_{c}$ (see Falqués and Calvete [2005] for details). The forcing conditions are waves with $H_{r m s}=1.5 \mathrm{~m}$ and $T p=8 \mathrm{~s}$ at a water depth of $25 \mathrm{~m}$. The wave direction ranges from $0^{\circ}$ to $85^{\circ}$ in increments of $5^{\circ}$. A closure depth $\bar{D}=20 \mathrm{~m}$ is chosen. To perform the linear stability analysis, the shape function for the bathymetric perturbations is assumed to be constant in the surf zone and to decrease exponentially seaward. Its cross-shore extent is given by the characteristic distance $x l$ corresponding to the closure depth of 20 $\mathrm{m}$, i.e. $x l=1410 \mathrm{~m}$ for the present case (P1-perturbation in Figure 2a).

\subsubsection{Results}

Figure 3a shows the growth rate of the LMA mode versus the wave angle and the beach Figure 3 slope. The wave angle is given for a water depth of $25 \mathrm{~m}$. The beach slope is defined as the beach slope at the shoreline. For small beach slopes $(<0.04)$ the coast behaves as expected: it is unstable only if the wave incidence angle is large enough. In this case, the shoreline instabilities clearly correspond to HAWI. For instance, for a beach slope of 0.02 , 
to a wavelength of $7000 \mathrm{~m}$ (Figure 3b).

However, for larger beach slopes, instabilities occur for all wave directions, and especially for low wave incidence angles. These instabilities correspond to what will be called LAWI in the present paper. Furthermore, among all the wave incidence angles, the most amplified mode is for shore-normal wave incidence. For a beach slope of 0.1 , an angle of $0^{\circ}$ leads to the largest growth rate $\left(1.82 \times 10^{-6} \mathrm{~s}^{-1}\right)$, corresponding to a wavelength of $571 \mathrm{~m}$ (Figure 3b).

\subsection{Sensitivity analysis}

The sensitivity analysis is performed using a planar beach, as the aim is to focus on the mechanisms. However, simulations with other (e.g. barred) profiles also lead to LAWI (not shown).

\subsubsection{Wave height and beach slope}

Keeping the same reference configuration as above and focusing on shore-normal wave incidence, we investigate the sensitivity of the instability to the wave height for a range of beach slopes. For normally incident waves, instabilities develop only for a beach slope that exceeds 0.04 (Figure 4). In this case, there is an optimum in the wave height for which the growth rate is largest. This wave height increases with the beach slope. For instance, for a beach slope of 0.1 and 0.18 ), the optimal wave height $H_{r m s}$ is $1.75 \mathrm{~m}$ and $2.5 \mathrm{~m}$, respectively. A wave height increase also leads to an increase in the LMA mode wavelength, which is due to the corresponding increase in surf zone width.

\subsubsection{Bathymetric perturbation length}


The influence of the parameter $x l$ was previously investigated by Falqués and Calvete [2005], who showed that $x l$ must exceed a threshold to initiate HAWI (the perturbation must extend across both the surf and shoaling zones). Similar behaviour is found here by exploring the range between $x l=10$ and $x l=10^{4} \mathrm{~m}$. Figure 5 shows that there is a threshold, $x l>100 \mathrm{~m}$, above which shoreline instabilities may occur. This value appears physically reasonable since the width of the surf zone in the reference case is about 73 m. For $125 \leq x l \leq 250 \mathrm{~m}$, the shoreline instability wavelength decreases significantly (from 1040 to $530 \mathrm{~m}$ ) with increasing perturbation length, whereas for $x l \geq 250 \mathrm{~m}$, the wavelength increases only slightly until reaching a nearly constant value of $574 \mathrm{~m}$. The growth rate increases with increasing $x l$ for values below $500 \mathrm{~m}$ but decreases for $x l$ exceeding $500 \mathrm{~m}$, reaching a nearly constant value for large perturbation length scales. The main conclusion is that instabilities occur only if the perturbation extends far enough into the shoaling zone. When the perturbation length is about the width of the surf zone, it influences the wavelength and growth rate of the LMA mode strongly, whereas for larger perturbation length values, this influence is negligible.

\subsubsection{Initial perturbation shape}

To evaluate the influence of the bathymetric perturbation shape function on the results we have presented so far, several shapes were investigated using the same wave-boundary conditions and a perturbation length $x l$ of $2000 \mathrm{~m}$. The shape functions we consider are (Figure 2a):

- Perturbation P1: bed perturbation constant in the surf zone and decreasing exponentially in the offshore direction 
- Perturbation P2: bed perturbation decreasing exponentially from the coast in the offshore direction

- Perturbation P3: P2 perturbation with a shoal located only in the shoaling zone, from 400 to $800 \mathrm{~m}$, with a maximum height at $x_{1}=600 \mathrm{~m}$.

- Perturbation P4: P2 perturbation with a shoal located in both the surf and shoaling zones, from 0 to $1400 \mathrm{~m}$, with a maximum height at $x_{1}=600 \mathrm{~m}$.

The reference configuration is still the same $\left(H_{r m s}=1.5 \mathrm{~m}, T=8 \mathrm{~s}, \theta=0^{\circ}\right)$. The four shape functions result in LMA mode wavelengths of 571, 571, 608 and $608 \mathrm{~m}$, respectively, and growth rates of $1.7,1.5,1.7,1.7 \times 10^{-6} \mathrm{~s}^{-1}$, respectively. Thus, the results are slightly sensitive (mean wavelength of $598 \mathrm{~m}$ and a standard deviation of $18 \mathrm{~m}$ ) to the bed perturbation type, but all perturbation types cause LAWI with similar growth rates.

\subsubsection{Sediment transport equation}

To investigate the sensitivity of the results to the sediment transport equation, computations were carried out with $r=0$, which reduces eq. 2 to the CERC equation. This sensitivity study is done in beach slope - wave angle space. The LMA characteristics are quite similar with $r=1$ (Figure 3) and $r=0$ (Figure 6), except for the case of normal

\section{Figure 6}

wave incidence. In this case $(r=0)$, for small beach slopes, all of the perturbations are damped, as for $r=1$. For larger beach slopes, the growth rate increases with decreasing perturbation wavelength without reaching a local maximum (Figure 7). Thus there is no LMA mode for shore-normal wave incidence (X symbol on Figure 6). This specific case for shore-normal wave incidence will be discussed in section 4 . To summarize, the previous results are not highly sensitive to the second term of the sediment transport equation, except for the case of shore-normal wave incidence. 


\section{The physical mechanism}

Here we investigate the physics behind the model prediction of shoreline instabilities caused by low wave incidence angles. The physical processes are analysed based on the study of the growth rate components, and the hydrodynamic and sediment transport patterns, before identifying the main mechanisms.

\subsection{Growth rate analysis}

In the perturbed situation where the shoreline position is given by eq. 4 , the wave height and wave angle at breaking are given by:

$H_{b}(y, t)=H_{b}^{0}+\left(\hat{H}_{b r}^{\prime}+i \hat{H}_{b i}^{\prime}\right) e^{\sigma t+i K y}+c . c$.

$\theta_{b}(y, t)=\theta_{b}^{0}+\left(\hat{\theta}_{b r}^{\prime}+i \hat{\theta}_{b i}^{\prime}\right) e^{\sigma t+i K y}+$ c.c.

where $H_{b}^{0}, \theta_{b}^{0}$ are the wave height and angle for the unperturbed situation. Then, according to Falqués and Calvete [2005], the growth rate (the real part of the complex growth rate) is:

$$
\sigma_{r}=\underbrace{2 \frac{\mu}{\bar{D}} H_{b}^{0} K^{2} \cos \left(2 \theta_{b}^{0}\right)}_{e_{0}}(\underbrace{-1}_{e_{1}}+\underbrace{\frac{\hat{\theta}_{b i}^{\prime}}{a K}}_{e_{2}}+\underbrace{\frac{5 \hat{H}_{b i}^{\prime}}{4 a K H_{b}^{0}} \tan \left(2 \theta_{b}^{0}\right)}_{e_{3}} \underbrace{-r \frac{\hat{H}_{b r}^{\prime}}{a \beta} \frac{\cos \left(\theta_{b}^{0}\right)}{\cos \left(2 \theta_{b}^{0}\right)}}_{e_{4}})
$$

A clue to the physical mechanism is provided by a careful analysis of the meaning and behaviour of each term:

- $e_{0}$ : common to all terms. It does not contribute to the stability/instability since it is positive. This is because we can assume that $\theta_{b}^{0}<45^{\circ}$ due to wave refraction. It is the magnitude of the growth rate.

- $e_{1}$ : always negative. It represents the contribution due to the changes in shoreline orientation when there is no perturbation in the wave field. This is the only term arising 
and Dalrymple, 2002]. It is a damping term describing the shoreline diffusivity in that approach.

- $e_{2}$ : its sign depends on $\hat{\theta}_{b i}^{\prime}$. Numerical computations [Falqués and Calvete, 2005] demonstrates that it is always positive. This results from the fact that refracted wave rays tend to rotate in the same direction as the shoreline. Thus $e_{2}$ is a growing term.

- $e_{3}$ : its sign depends on $\hat{H}_{b i}^{\prime}$. Numerical computations [Falqués and Calvete, 2005] show that $\hat{H}_{b i}^{\prime}>0$ for long sandwaves and $<0$ for short sandwaves. This term is related to energy spreading due to wave crest stretching as waves refract. Thus $e 3$ is a growing or damping term, depending on the sandwave wavelength, $2 \pi / K$. Moreover, its magnitude increases with an increasing incident wave angle. These two properties explain that $e_{3}$ is an essential growing term for HAWI formation Falqués and Calvete [2005], whereas, for LAWI, its magnitude is smaller and it is, most of the time, negative.

- $e_{4}$ : this term stems from the alongshore gradients in $H_{b}$ in the sediment transport equation (eq. 2). Its sign is the opposite to that of $\hat{H}_{b r}^{\prime}$, which is numerically found to be always positive. This is related to the fact that the maximum in wave energy is always located close to the sandwave crest (wave focusing). Thus $e_{4}$ is a damping term.

The corresponding growth rate contributions, $\sigma_{1}=e_{0} e_{1}, \sigma_{2}=e_{0} e_{2}, \ldots$ are plotted in Figure 8. It can be seen that $\sigma_{2}$ is always positive leading to the development of shoreline sandwaves, whereas $\sigma_{1}$ and $\sigma_{4}$ are always negative, leading to the damping of the sandwaves. The term $\sigma_{3}$ can be either positive, for small beach slope (eg smaller than 0.05 to 0.08), or negative, for larger beach slopes. Even if the behaviour of this term is not monotonous, $\sigma_{3}$ generally increases with the wave angle. It is remarkable that $\sigma_{2}$ becomes 
with increasing the wave incidence angle. In other words, wave height gradients (wave setup induced sediment fluxes) largely influence (damp) the shoreline instability for low wave angle incidence (LAWI), whereas their impact is almost negligible for large wave incidence angles (HAWI). The main driving term of the LAWI is due to the wave incidence induced sediment transport flux $Q_{1}$. This means that the use of the CERC equation alone, taking into account wave refraction in the shoaling zone, can cause LAWI. The $Q_{2}$ term influences this instability by changing the growth rate and the favored wavelength. This influence increases with decreasing wave incidence until the case of perfectly shore-normal waves, for which there is a prefered wavelength (LMA mode) only if the $Q_{2}$ term is taken into account (Figure 6).

\subsection{Model results analysis: Hydrodynamic and sediment transport}

To understand better how wave refraction causes shoreline instabilities, hydrodynamic and sediment transport model results are analysed next. Here, we focus on the case of shore-normal wave incidence, considering the LMA mode obtained for a beach slope equal to 0.1 (case a). The model results are compared with the same wave incidence, but 
wavelength $(571 \mathrm{~m})$ is the same for both cases, corresponding to the LMA mode of case (a). Although the linear stability analysis is strictly valid only in the limit $a \rightarrow 0$ we choose a shoreline sandwave amplitude $a=10 \mathrm{~m}$ (for visualization and comparison of the different sources of sediment transport). In addition, to make the analysis simpler, we assume shore-normal waves and $r=0$. Figures 10a and $\mathrm{b}$ show planviews of the wave angle, as well as a longshore cross-section of several quantities along the breaking line. First, it can be noted that the breaking line is much farther offshore in case (b) because of the shallower bathymetry. This is directly linked with the bathymetry. These planviews illustrate the wave focussing on the cusp, which implies increasing wave height and converging waves at the cusps.

Looking at the alongshore cross-section (Figure 10c), the wave angle amplitude is much larger for case (a) than for case (b), about $14^{\circ}$ versus $3.2^{\circ}$, indicating a stronger refraction up to the breaking line in case (a). The corresponding amplitude of the oscillation in the shoreline angle is about $6.3^{\circ}$, and is thus within the range of those two values. This means that the angle of the wave fronts with respect to the local shoreline reverses when passing from case (a) to (b), implying a reversal in the direction of sediment transport. This can be traced back to equation 6 . The wave angle amplitude is much larger for case (a). Coming back to equation 6 , in the case of shore-normal waves and $r=0$, there are only two terms left: $e_{1}$, which is the contribution due to shoreline change only, and $e_{2}$, which represents the wave refraction-induced sediment flux. The analytical computation for the present case leads to: $e_{1}=-1$ for both cases, whereas $e_{2}=2.23$ for case (a) and $e_{2}=0.507$ (case b), consistent with the different amplitudes of alongshore wave angle 
for case (b). The alongshore cross-section of the resulting sediment flux $Q$ (Figure 10c) illustrates the opposite behaviour for the two cases. Our sign convention is that positive $Q$ represents sediment transport directed in the direction of the increasing $y$ coordinate (i.e. to the right on the cross-sections). A positive (negative) longshore gradient indicates a convergence (divergence), assumed to cause shoreline accretion (erosion). Thus Figure 10c shows that $Q$ for case (a) has a spatial phase-lag compared to the shoreline such that the shoreline perturbation should be amplified, whereas $Q$ for case (b) has an opposite phase-lag, leading to the damping of the perturbation. This spatial phase-lag change results from the continuous amplitude changes of the terms $e_{1}$ and $e_{2}$ : the phase-lag between shoreline and longshore sediment fluxes is either $90^{\circ}$ or $-90^{\circ}$, implying that there is no migration and either amplification or damping of the shoreline perturbation. Thus, for shore-normal waves and neglecting the damping term related with wave setup induced sediment flux (second term in eq. 2), the instability of the shoreline results from an alongshore oscillation in the angle of wave refraction, which is stronger than the oscillation in the angle of shoreline orientation.

\subsection{Mechanism}

From the above, we can draw the following conclusion: the main growing term is related to the wave refraction toward the cusp, leading to wave incidence induced sediment transport converging at the cusp. This term strongly increases with beach slope. The damping is due to three components: (1) longshore sediment transport due to the shoreline orientation only (and not refraction, term $e_{1}$ ), (2) wave energy spreading (term $e_{3}$ ), 
damping effect than the two others.

Now we can figure out how LAWI works (Figure 11). Let us consider shore-normal

wave incidence. In this case, the wave energy spreading has no influence on the instability $\left(e_{3}=0\right)$. If a cuspate feature with an associated shoal develops on a coastline, wave refraction bends wave rays towards the tip of the feature. Depending on the orientation of the refracted wave fronts with respect to the local shoreline along the cuspate feature, the alongshore sediment flux can be directed towards the tip, reinforcing it and leading to a positive feedback between flow and morphology. Whether the transport is directed to the tip, depends on the bathymetry and wave conditions. For a given offshore extent, $x l$, of the associated shoal and a given wave height, the surf zone will become narrower if the beach slope increases. Then, the shoal will extend a longer distance beyond the surf zone, and the waves will be refracted strongly when they reach the breaking point, increasing the wave incidence related sediment flux $\left(e_{2}\right)$ convergence whereas the divergence term $\left(e_{1}\right)$ is constant. As shown by the model results (Figure 10), the contribution of the refracted wave angle $\left(e_{2}\right)$ can exceed the contribution of the shoreline orientation to the sediment flux (e1), such that $Q_{1}$ (resulting from $e_{1}$ and $e_{2}$ ) converges near the cusp. This leads to the development of the cusp. If the beach slope is mild, the surf zone will be wider, and wave refraction over the shoal before breaking will be less intense, leading to smaller wave incidence angle induced sediment fluxes, which are dominated instead by the diverging sediment flux induced by shoreline orientation changes. In this case, as shown in the model results (Figure 10c), the sediment flux is directed away from the tip of the cusp. 


\section{Discussion}

\subsection{Linear stability analysis validity}

\subsection{Analogy with megacusps: growth rates and circulation patterns}


rate comparable to that of co-existing instabilities. Our sensitivity studies indicate LAWI growth rates to range from $10^{-6} \mathrm{~S}^{-1}$ (for a beach slope of 0.05 ) to $10^{-5} \mathrm{~S}^{-1}$ (for a beach slope of 0.2 ). The typical generation time scale thus ranges from 1.5 to 11.5 days. These time scales were obtained for shore-normal waves having a moderate wave height of 1.5 $\mathrm{m}$ and wave period of $8 \mathrm{~s}$. A typical time scale for the LMA mode of crescentic bars is several days [Damgaard et al., 2002; Garnier et al., 2010]. Thus, for specific beach slope and wave conditions, the LMA shoreline instabilities have comparable initial growth rates as those of crescentic bar patterns.

Computations for the idealized cases gives LAWI wavelengths of the same order of magnitude as the observed spacing of crescentic bars and associated megacusps. The distinction between these two kinds of instabilities is therefore difficult and the validation of the presence of LAWI in a Rhythmic Bar and Beach morphological environment is not straightforward. More generally, a proper validation of the present results would need dataset of shoreline evolution, together with bathymetric, wave and current data, starting from an initial longshore uniform beach. To our knowledge, such data do not exist.

Although we cannot validate the model results with wavelengths observed in the field, it is possible to discuss whether the type of nearshore circulation linked to LAWI, that is, a longshore sediment flux pointing toward the cuspate feature at both sides, is realistic or not in nature and in the framework of 2DH modeling. According to Komar [1998], both types of longshore current patterns, either converging or diverging at a megacusp, are observed in nature. Another example showing that this type of circulation is realistic is the case of a submerged breakwater. Both observations and numerical modelling indicate 
converge at the lee of the breakwater to build a salient [Ranasinghe et al., 2006]. This

converging type of circulation at a megacusp was also observed by Haller et al. [2002] in

laboratory experiments on barred beaches with rip channels. One of their six experimental configurations may be quite close to a LAWI configuration. This configuration had the largest average water depth at the bar crest and the smallest rip velocity at the rip neck, such that, in addition to the rip current circulation, they found a secondary circulation system near the shoreline, likely forced by the breaking of the larger waves that propagated through the channel. As these waves are breaking close to the shoreline, they drove longshore currents away from the rip channels into the shallowest area. This experiment shows that breaking close to the shoreline counteracts the rip-induced circulation, leading to current convergence in the shallowest area.

The studies of Calvete et al. [2005] and Orzech et al. [2011] give other elements to investigate the plausibility of the LAWI mechanism, in rip channels configurations. For the case of a barred-beach, Calvete et al. [2005] developed a 2DH linear stability model, having a fixed shoreline, that describes the formation of rip channels from an initially straight shore-parallel bar. For shore-normal waves, the circulation linked to rip channel formation is offshore through the channels and onshore over the shoals or horns of the developing crescentic bar as is clearly observed in nature (e.g. [MacMahan et al., 2006]). However, they also noticed small secondary circulation cells near the shoreline flowing in the opposite direction, leading to presence of megacusp formed in front of the horns of the crescentic bar; therefore, the shoreline undulations were out of phase (spatial phaselag of $180^{\circ}$ ) with the crescentic bars, meaning that the amplitude of the wave-refracted 


\section{Conclusions}

A one-line linear stability model, which was initially created to describe the formation of shoreline sandwaves under high-angle wave incidence, has revealed shoreline instabilities for low to shore-normal wave incidence (LAWI). The most amplified mode has wavelengths of $\sim 500 \mathrm{~m}$ and characteristic growth time scales of a few days, which are smaller than those of the high angle wave instabilities. Sensitivity analyses focusing on wave height, wave incidence angle, beach slope, beach profile, model free parameters and the sediment transport equation show that, for low to shore-normal wave incidence, instabilities develop for sufficiently large beach slopes (e.g. 0.06) and for sufficiently small wave heights (smaller than $2 \mathrm{~m}$ for a beach slope of 0.06 ).

The main process causing the instabilities for low to shore-normal wave incidence is wave refraction on a shoal in the shoaling zone, which focuses wave fronts onshore of it, leading to wave incidence induced sediment transport converging at the cusp. This effect strongly increases with beach slope. The damping is due to three longshore transport components: (1) that caused by shoreline orientation only (and not refraction), (2) that caused by wave energy spreading (minor effect for low-angle wave incidence), (3) that caused by wave height gradients (set-up). Whether LAWI develops or not depends on the balance between these growing and damping terms. If this shoreline sand accumulation can feed the initial shoal through cross-shore sediment transport, a positive feedback arises.

Acknowledgments. The authors thank the reviewers (including A. Ashton) for their comments and suggestions, D. Calvete for fruitful discussions, J. Thiébot for his comments on this paper. M. Yates-Michelin is also acknowledged for her careful English corrections. Funding from the ANR VMC 2006 - project VULSACO nANR-06-VULN-009, the Span- 


\section{References}

Ashton, A., and A. B. Murray, High-angle wave instability and emergent shoreline shapes: 1. modeling of sand waves, flying spits, and capes, J.Geophys.Res., 111, F04,011,doi:10.1029/2005JF000,422, 2006a.

Ashton, A., and A. B. Murray, High-angle wave instability and emergent shoreline shapes: 2. wave climate analysis and comparisons to nature, J.Geophys.Res., 111, F04,012,doi:10.1029/2005JF000,423, 2006b.

Ashton, A., A. B. Murray, and O. Arnault, Formation of coastline features by large-scale instabilities induced by high-angle waves, Nature, 414, 296-300, 2001.

Bender, C., and R. Dean, Potential shoreline changes induced by three-dimentional bathymetric anomalies with gradual transitions in depth, Coast. Eng., 51, 1143-1161, 2004.

Blondeaux, P., Mechanics of coastal forms, Ann. Rev. Fluid Mech., 33, 339-370, 2001.

Bruun, P., Migrating sand waves or sand humps, with special reference to investigations carried out on the Danish North Sea Coast, in Coastal Eng. 1954, pp. 269-295, Am. Soc. of Civ. Eng., 1954.

Calvete, D., Morphological stability models: Shoreface-connected sand ridges, Ph.D. thesis, Appl. Physics Dept., Univ. Politècnica de Catalunya, Barcelona, Spain, 1999.

Calvete, D., N. Dodd, A. Falqués, and S. M. van Leeuwen, Morphological development of rip channel systems: Normal and near normal wave incidence, J. Geophys. Res., 
110(C10006), doi:10.1029/2004JC002803, 2005.

Castelle, B., P. Bonneton, H. Dupuis, and N. Sénéchal, Double bar beach dynamics on the high-energy meso-macrotidal french aquitanian coast : a review, Mar. Geol., 245, $141-159,2007$.

Damgaard, J., N. Dodd, L. Hall, and T. Chesher, Morphodynamic modelling of rip channel growth, Coastal Eng., 45, 199-221, 2002.

Davidson-Arnott, R. G. D., and A. van Heyningen, Migration and sedimentology of longshore sandwaves, Long Point, Lake Erie, Canada, Sedimentology, 50, 1123-1137, 2003.

Dean, R. G., and R. A. Dalrymple, Coastal Processes, Cambridge University Press, Cambridge, 2002.

Dodd, N., P. Blondeaux, D. Calvete, H. E. de Swart, A. Falqués, S. J. M. H. Hulscher, G. Różyński, and G. Vittori, The use of stability methods in understanding the morphodynamical behavior of coastal systems, J. Coastal Res., 19(4), 849-865, 2003.

Falqués, A., Wave driven alongshore sediment transport and stability of the Dutch coastline, Coastal Eng., 53, 243-254, 2006.

Falqués, A., and D. Calvete, Large scale dynamics of sandy coastlines. Diffusivity and instability, J. Geophys. Res., 110(C03007), doi:10.1029/2004JC002587, 2005.

Falqués, A., G. Coco, and D. A. Huntley, A mechanism for the generation of wave-driven rhythmic patterns in the surf zone, J. Geophys. Res., 105(C10), 24,071-24,088, 2000.

Falqués, A., N. Dodd, R. Garnier, F. Ribas, L. MacHardy, P. Larroud, D. Calvete, and F. Sancho, Rhythmic surf zone bars and morphodynamic self-organization, Coastal Eng., 55, 622-641, doi:10.1016/j.coastaleng.2007.11.012, 2008. 
Garnier, R., D. Calvete, A. Falqués, and M. Caballeria, Generation and nonlinear evolution of shore-oblique/transverse sand bars, J. Fluid Mech., 567, 327-360, 2006.

Garnier, R., D. Calvete, A. Falqués, and N. Dodd, Modelling the formation and the long-term behavior of rip channel systems from the deformation of a longshore bar, $J$. Geophys. Res., 113(C07053), doi:10.1029/2007JC004632, 2008.

Garnier, R., N. Dodd, A. Falqués, and D. Calvete, Mechanisms controlling crescentic bar amplitude, J. Geophys. Res., 115, doi:10.1029/2009JF001407, 2010.

Haller, M. C., R. A. Dalrymple, and I. A. Svendsen, Experimental study of nearshore dynamics on a barred beach with rip channels, J. Geophys. Res., 107(C6), 10.1029/2001JC000,955, 2002.

Horikawa, K., Nearshore Dynamics and Coastal Processes, University of Tokio Press, Tokio, Japan, 1988.

Inman, D. L., M. H. S. Elwany, A. A. Khafagy, and A. Golik, Nile delta profiles and migrating sand blankets, in Coastal Eng. 1992, pp. 3273-3284, Am. Soc. of Civ. Eng., 1992.

Komar, P. D., Beach Processes and Sedimentation, second ed., Prentice Hall, Englewood Cliffs, N.J., 1998.

Lafon, V., D. D. M. Apoluceno, H. Dupuis, D. Michel, H. Howa, and J. M. Froidefond, Morphodynamics of nearshore rhythmic sandbars in a mixed-energy environment (SW France): I. Mapping beach changes using visible satellite imagery, Estuarine, Coastal and Shelf Science, 61, 289-299, 2004.

List, J. H., and A. D. Ashton, A circulation modeling approach for evaluating the conditions for shoreline instabilities, in Coastal Sediments 200\%, pp. 327-340, ASCE, 2007. 
transport: comparing the cerc formula to delft3d, in Coastal Eng. 2006, pp. 3370-3380, World Scientific, 2006.

List, J. H., L. Benedet, D. M. Hanes, and P. Ruggiero, Understanding differences between delft3d and emperical predictions of alongshore sediment transport gradients, in Coastal Eng. 2008, pp. 1864-1875, World Scientific, 2008.

MacMahan, J. H., E. B. Thornton, and A. J. H. M. Reniers, Rip current review, Coastal Eng., 53, 191-208, 2006.

Medellín, G., R. Medina, A. Falqués, and M. González, Coastline sand waves on a low energy beach at 'El Puntal' spit, Spain, Mar. Geol., 250, 143-156, 2008.

Medellín, G., A. Falqués, R. Medina, and M. González, Sand waves on a low-energy beach at el 'puntal' spit, Spain: Linear Stability Analysis, J. Geophys. Res., 114(C03022), doi:10.1029/2007JC004426, 2009.

Orzech, M., A. Reniers, E. Thornton, and J. MacMahan, Megacusps on rip channel bathymetry: Observations and modeling, Coastal Eng., p. doi:10.1016/j.coastaleng.2011.05.001, 2011.

Ozasa, H., and A. H. Brampton, Mathematical modelling of beaches backed by seawalls, Coastal Eng., 4, 47-63, 1980.

Ranasinghe, R., G. Symonds, K. Black, and R. Holman, Morphodynamics of intermediate beaches: A video imaging and numerical modelling study, Coastal Eng., 51, 629-655, 2004.

Ranasinghe, R., I. L. Turner, and G. Symonds, Shoreline response to multi-functional artificial surfing reefs: A numerical and physical modelling study, Coastal Eng., 53, 
Reniers, A. J. H. M., J. A. Roelvink, and E. B. Thornton, Morphodynamic modeling of an embayed beach under wave group forcing, J. Geophys. Res., 109(C01030), doi:10.1029/2002JC001586, 2004.

Ribas, F., and A. Kroon, Characteristics and dynamics of surfzone transverse finger bars, J. Geophys. Res., 112(F03028), doi:10.1029/2006JF000685, 2007.

Ruessink, B. G., and M. C. J. L. Jeuken, Dunefoot dynamics along the dutch coast, Earth Surface Processes and Landforms, 27, 1043-1056, 2002.

Sonu, C. J., Collective movement of sediment in littoral environment, in Coastal Eng. 1968, pp. 373-400, Am. Soc. of Civ. Eng., 1968.

Sonu, C. J., Three-dimensional beach changes, J. Geology, 81, 42-64, 1973.

Stewart, C. J., and R. G. D. Davidson-Arnott, Morphology, formation and migration of longshore sandwaves; long point, lake erie, canada, Mar. Geol., 81, 63-77, 1988.

Thevenot, M. M., and N. C. Kraus, Longshore sandwaves at Southampton Beach, New York: observations and numerical simulation of their movement, Mar. Geology, 126, 249-269, 1995.

Tiessen, M. C. H., S. M. V. Leeuwen, D. Calvete, and N. Dodd, A field test of a linear stability model for crescentic bars, Coastal Engineering, 57, 41-51, 2010.

USACE, Shore protection manual, Tech. Rep. 4th ed., 2 Vol., USACE, U.S. Government Printing Office, Washington, D.C., 1984.

van den Berg, N., A. Falqués, and R. Ribas, Long-term evolution of nourished beaches under high angle wave conditions, Journal of Marine Systems, to appear, 2011.

Verhagen, H. J., Sand waves along the dutch coast, Coastal Eng., 13, 129-147, 1989. 
${ }_{643}$ Wright, L. D., and A. D. Short, Morphodynamic variability of surf zones and beaches: A ${ }_{644} \quad$ synthesis, Mar. Geol., 56, 93-118, 1984.

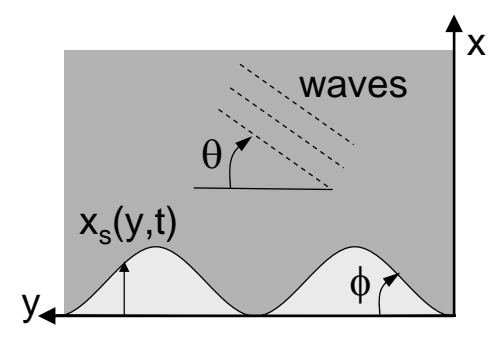

Figure 1. Sketch of the geometry and the variables. The angle between the wave fronts and the local shoreline is $\alpha=\theta-\phi$. 


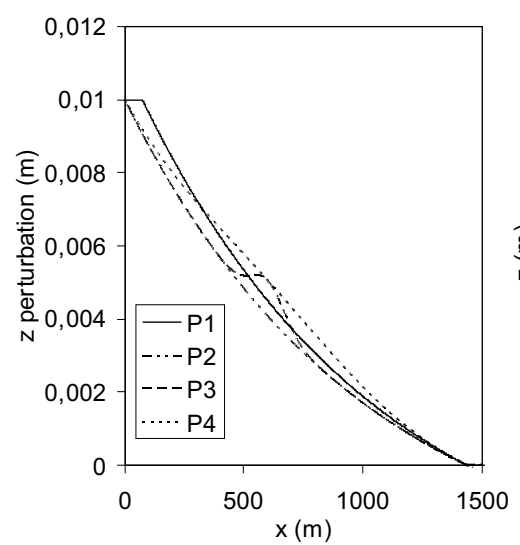

(a)

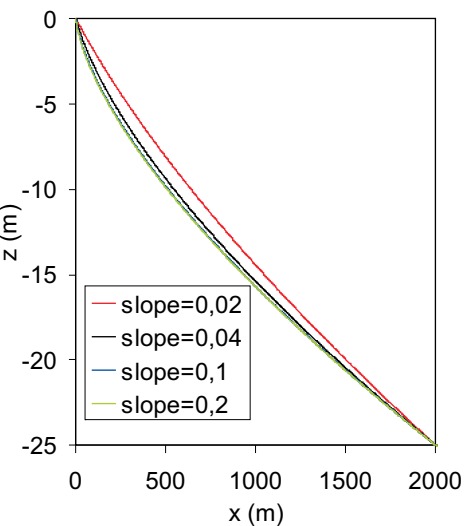

(b)

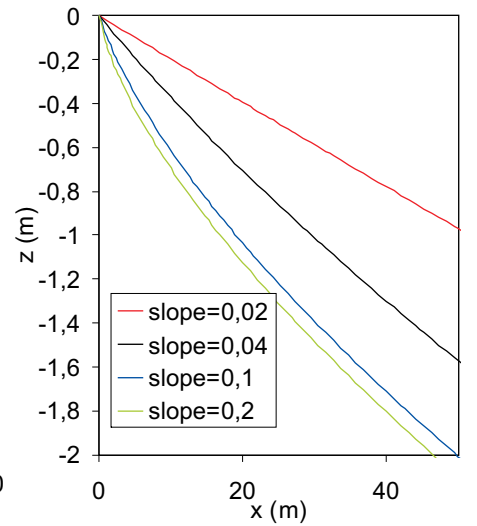

(c)

Figure 2. Bathymetric perturbations (a) and cross-shore Dean beach profile for a various beach slopes $(\mathrm{b}, \mathrm{c})$. P1-perturbation: constant in the surf zone and exponential decrease, P2perturbation: exponential decrease, P3-perturbation: exponential decrease with a shoal in the shoaling zone, P4-perturbation: exponential decrease with a shoal in the surf and shoaling zones.

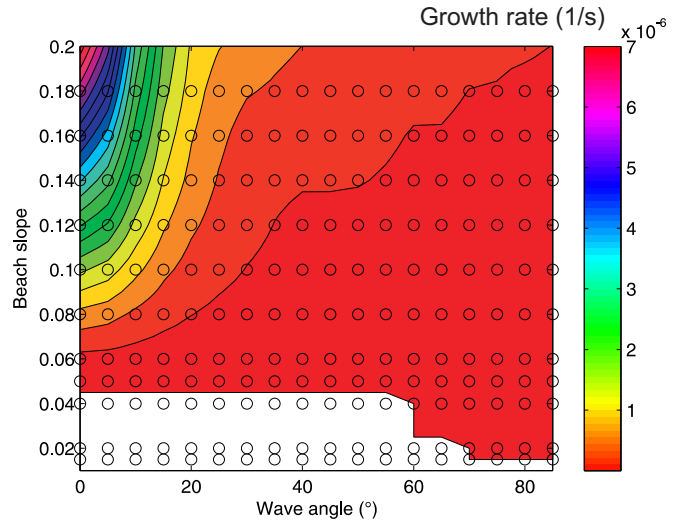

(a)

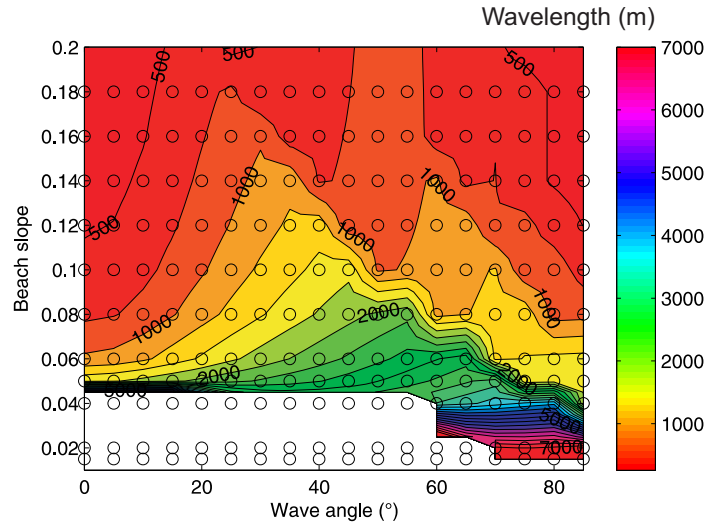

(b)

Figure 3. LMA (a) growth rate and (b) wavelength as a function of beach slope and angle of incidence. Circles indicate the 1D-morfo computations. In white: no growing perturbation. The model parameters are : $\mu=0.15, r=1$, P1-Perturbation and $x l=1410 \mathrm{~m}$ for Dean profiles with $H_{r m s}=1.5 \mathrm{~m}$ and $T_{p}=8 \mathrm{~s}$ at a water depth of $25 \mathrm{~m}$. 


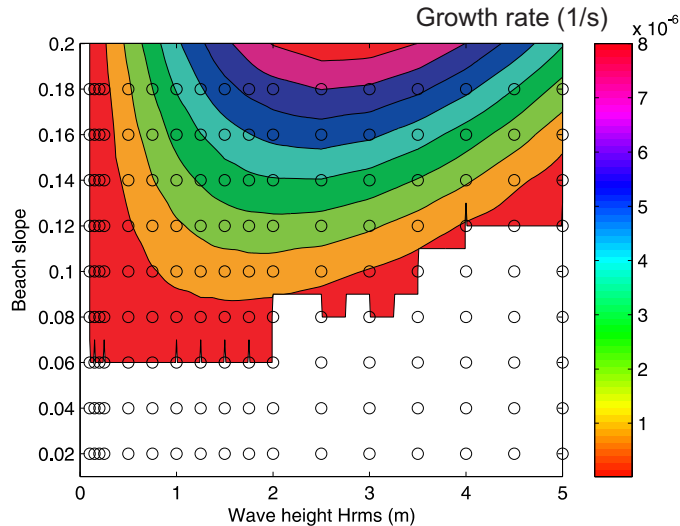

(a)

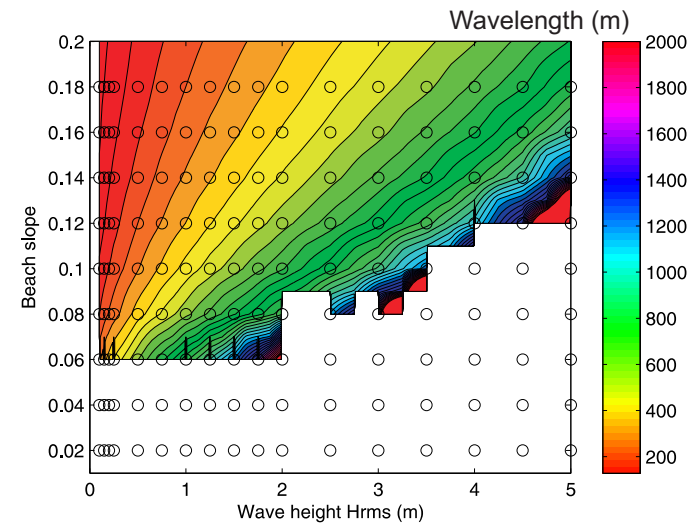

(b)

Figure 4. LMA (a) growth rate and (b) wavelength as a function of beach slope and wave height, for shore-normal waves. Circles indicate the 1D-morfo computations. In white: no growing perturbation. The model parameters are : $\mu=0.15, r=1$, P1-Perturbation and $x l=1410 \mathrm{~m}$ for Dean profiles with $\theta=0^{\circ}$ and $T_{p}=8 \mathrm{~s}$ at a water depth of $25 \mathrm{~m}$.

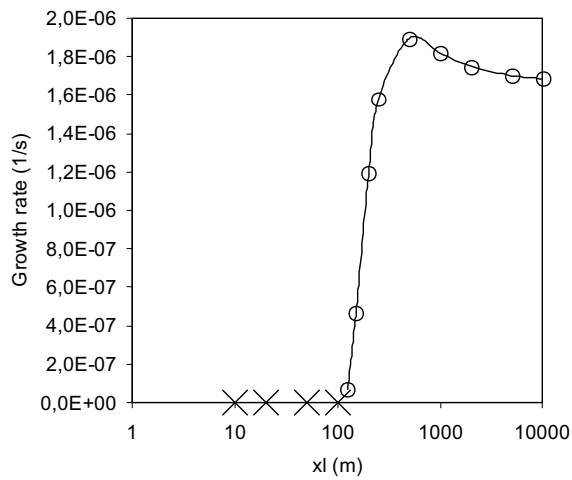

(a)

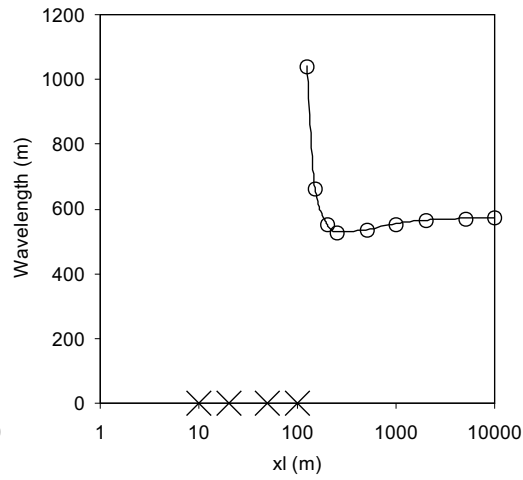

(b)

Figure 5. LMA mode (a) growth rate and (b) wavelength as a function of the shoreline perturbation length $x l$ for a Dean profile with a beach slope of 0.1 . Crosses on the $x l$ axis $(10 \leq x l \leq 100)$ indicate that there is no LMA mode for the given shoreline perturbation length. 

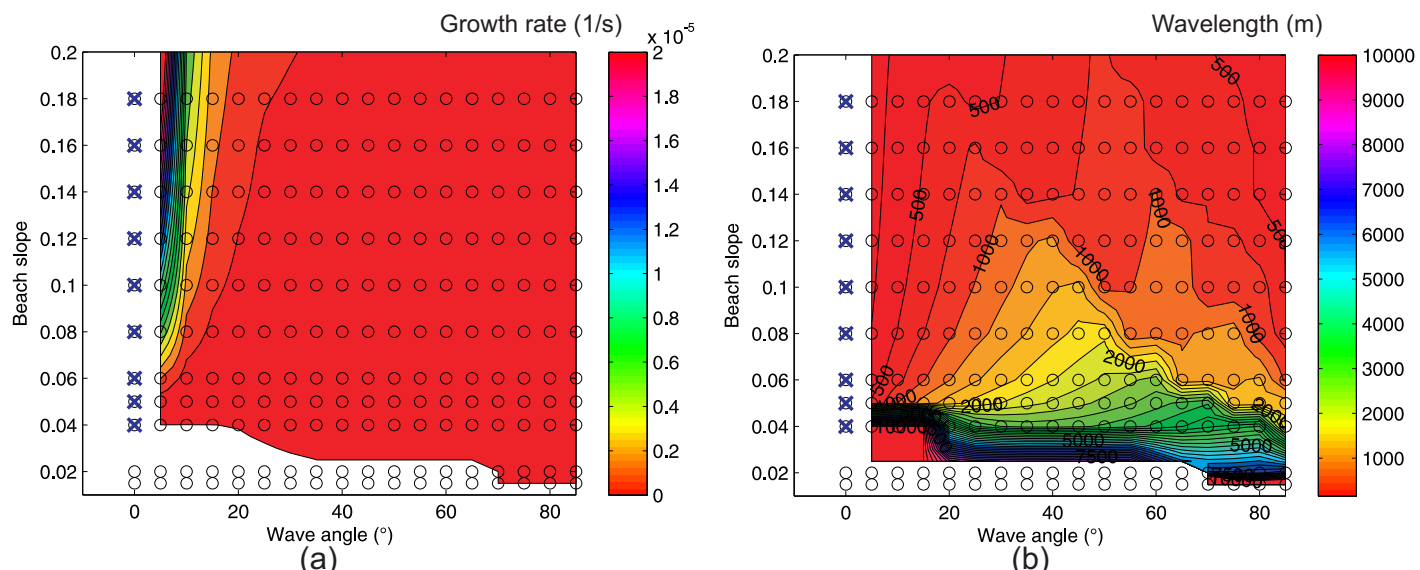

(a)

(b)

Figure 6. LMA (a) growth rate and (b) wavelength as function of beach slope and wave angle, for $r=0$. Circles indicate the 1D-morfo computations. In white: no LMA mode. The symbol $\mathrm{x}$ indicates that, even if the growth rate was positive, there was a singularity at $\theta=0^{\circ}$ (growth rate continuously increasing with decreasing wavelength), and therefore no LMA mode (see Figure 7). 


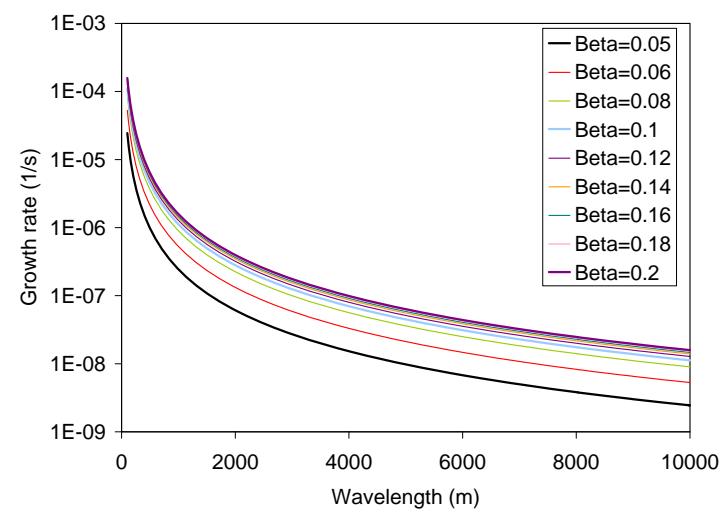

Figure 7. LMA growth rate versus wavelength for various beach slopes, using $r=0$ and shore-normal waves. The shoreline is stable for a beach slope $\beta<0.05$. The model parameters are : $\mu=0.15$, P1-Perturbation and $x l=1410 \mathrm{~m}$ for the Dean profile with $H_{r m s}=1.5 \mathrm{~m}$ and $T_{p}=8 \mathrm{~s}$ at a water depth of $25 \mathrm{~m}$. 


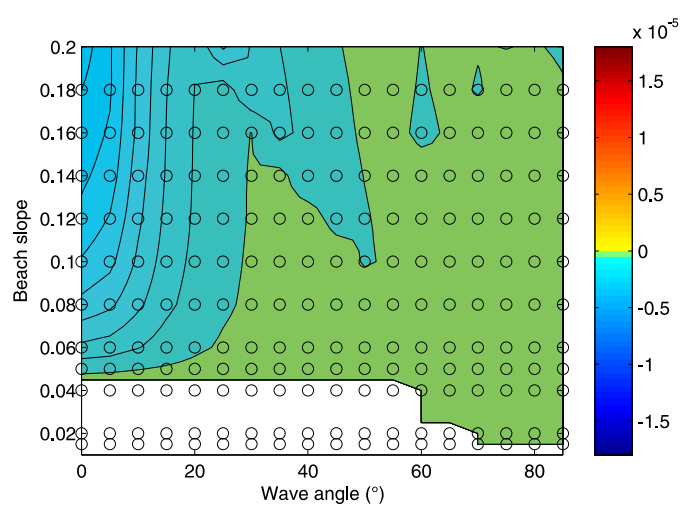

(a)

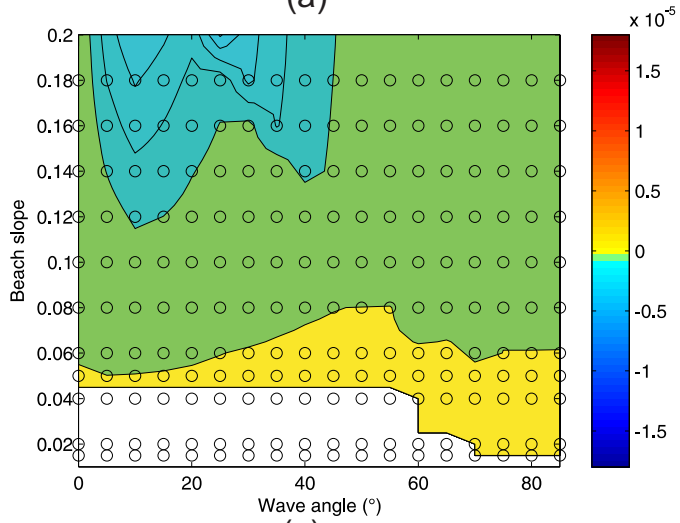

(c)

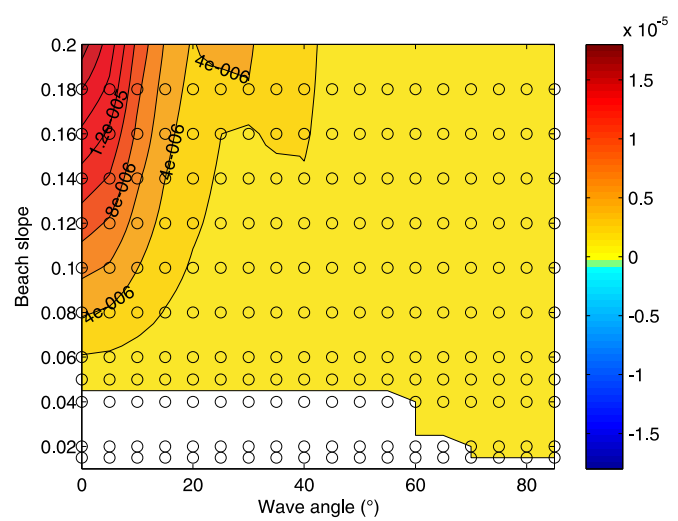

(b)

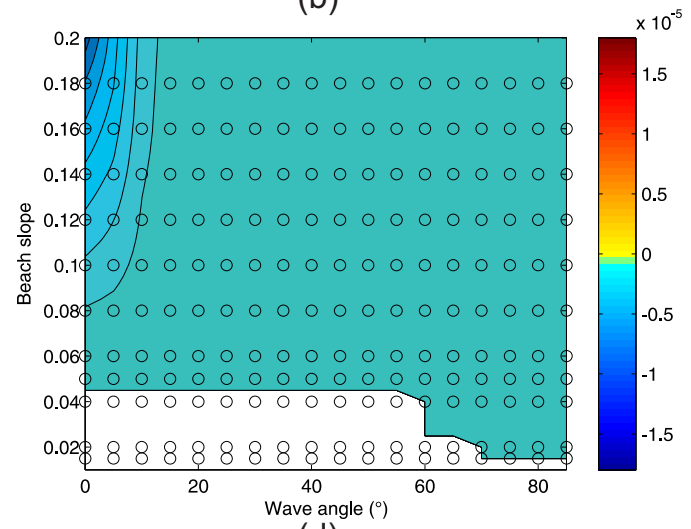

(d)

Figure 8. Growth rate components for the LMA mode as a function of beach slope and angle of incidence. Model paremeters are: $H_{r m s}=1.5 \mathrm{~m}, T_{p}=8 \mathrm{~s}$ and cross-shore perturbation of type P1 with $x l=1410 \mathrm{~m}$. (a) $\sigma_{1}$, (b) $\sigma_{2}$, (c) $\sigma_{3}$, (d) $\sigma_{4}$. Circles indicate the 1D-morfo computations. In white: no LMA mode. 


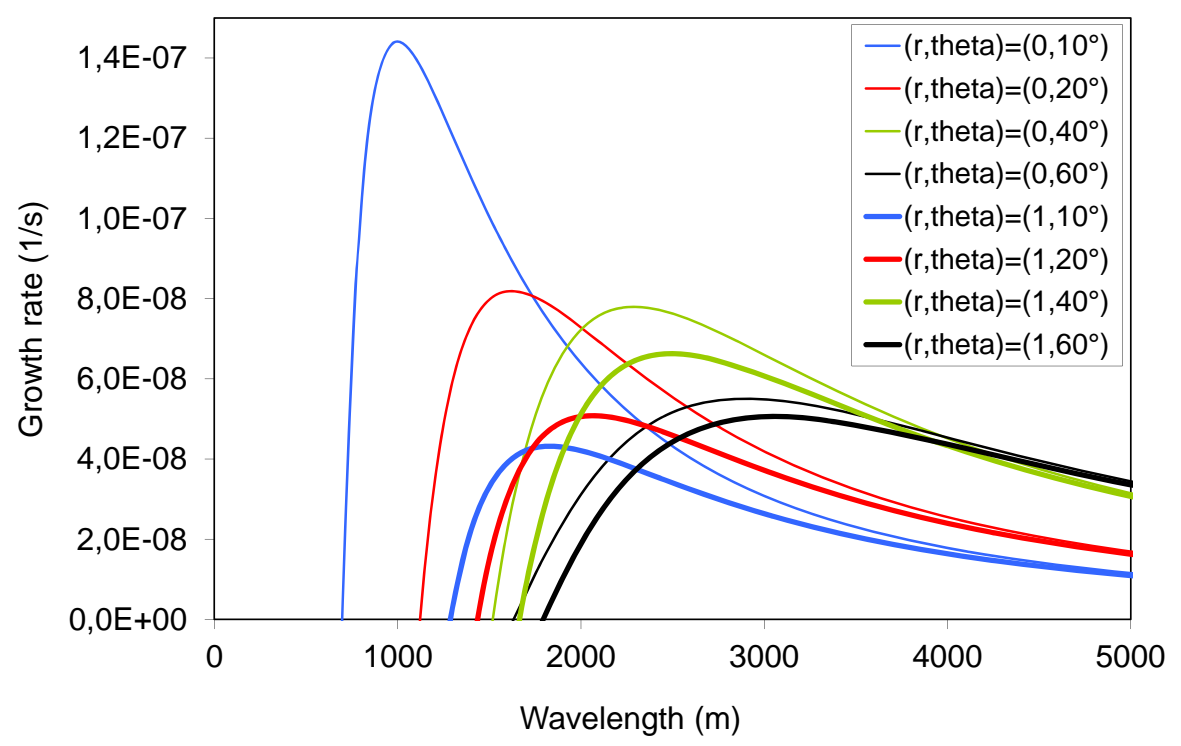

Figure 9. Growth rate versus wavelength for several combinations of $r$ and wave incidence angle $\theta$. The beach slope is 0.05 . 


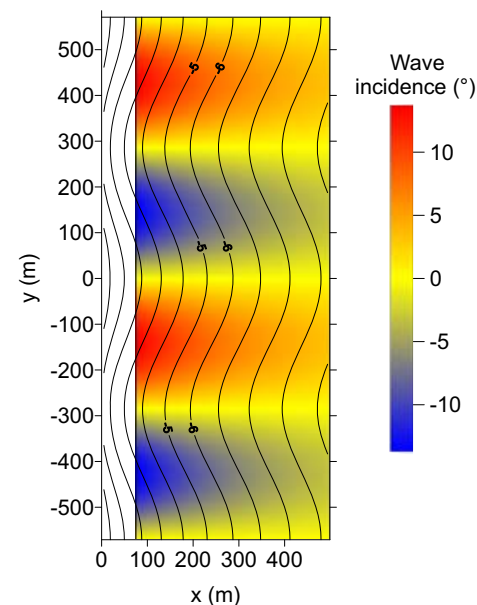

(a)

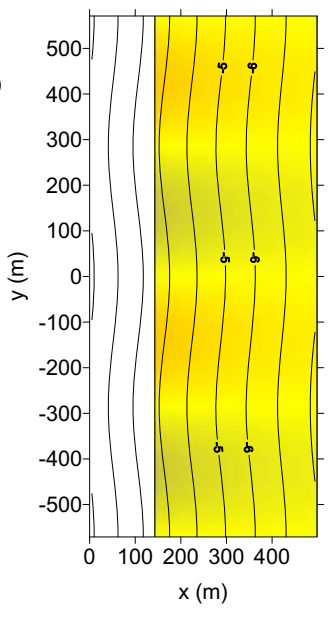

(b)
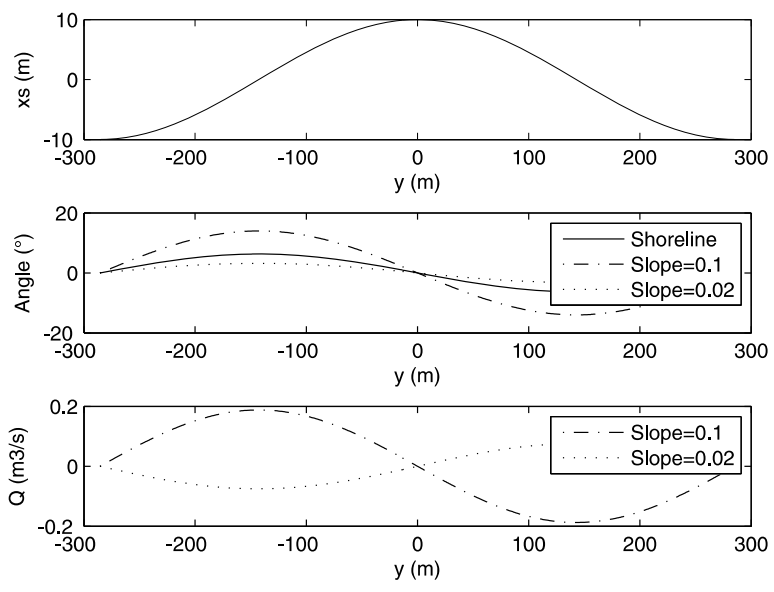

(c)

Figure 10. Model results for a perturbation wavelength of $571 \mathrm{~m}$ (LMA mode for a beach slope of 0.1), shore-normal wave incidence, and a shoreline wave amplitude of $a=10 \mathrm{~m}$. (a) and (b) show the topographic contours and the refracted wave angle for beach slopes of 0.1 (a) and 0.02 (b). (c) shows the longshore profiles of (Top) the shoreline position, (Middle) the shoreline angle (solid line) and refracted wave angles and (Bottom) the sediment fluxes. Dashed-dotted lines, and dotted lines represent a beach slope of 0.1 and 0.02 , respectively. 


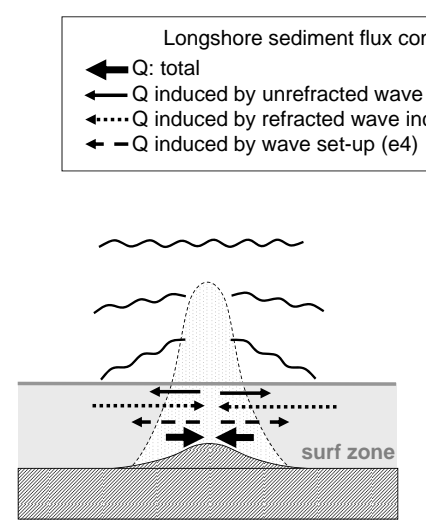

(a)

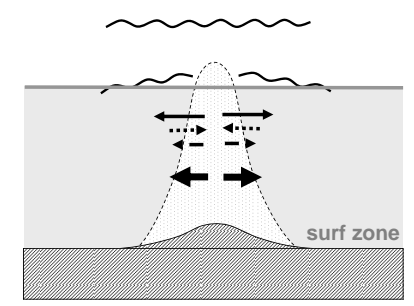

(b)

Figure 11. Sketch of the physical mechanisms causing LAWI. Sediment transport components induced by a shoal for unstable (a) and stable (b) situations, corresponding to a narrow and wide surf zone, respectively. 